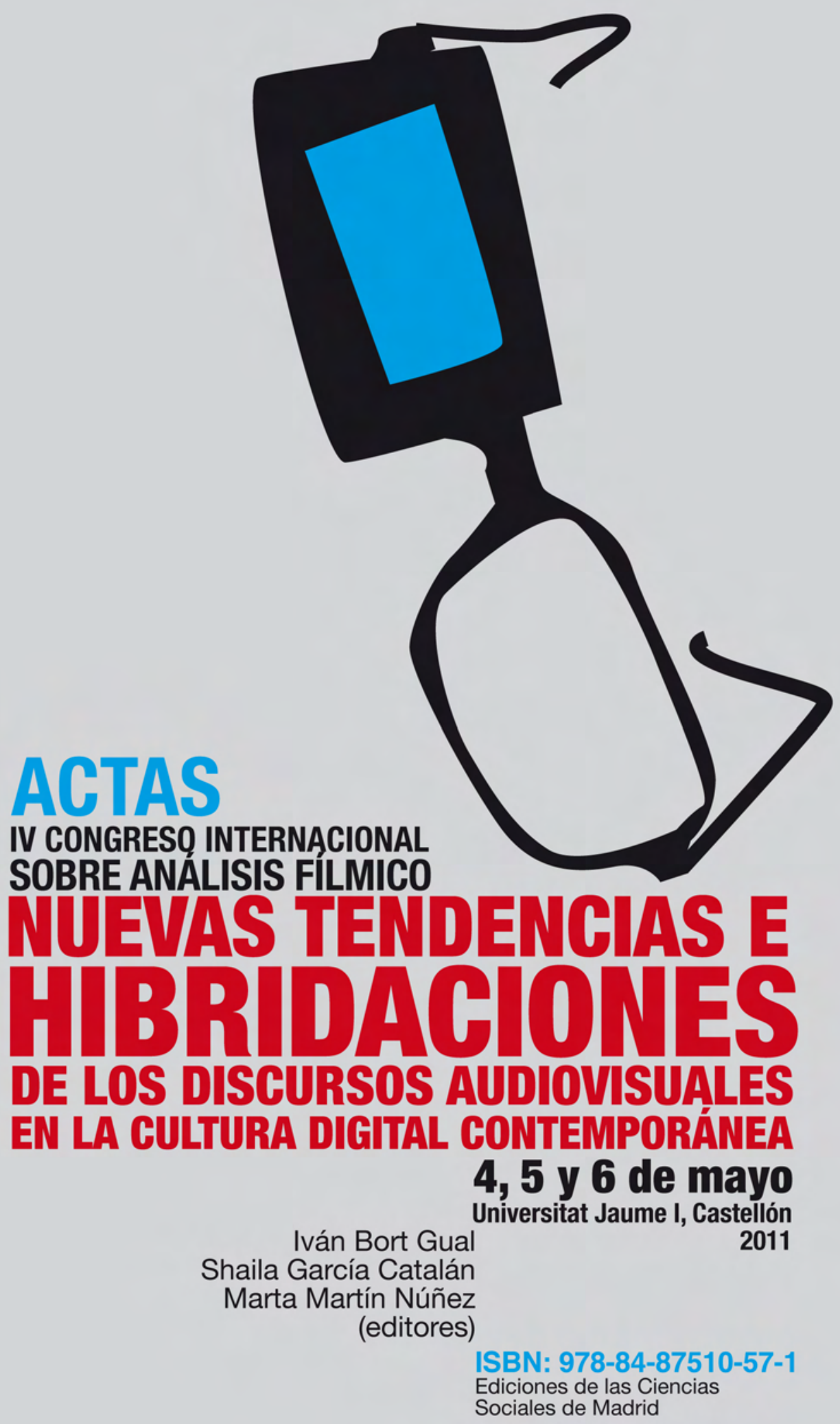




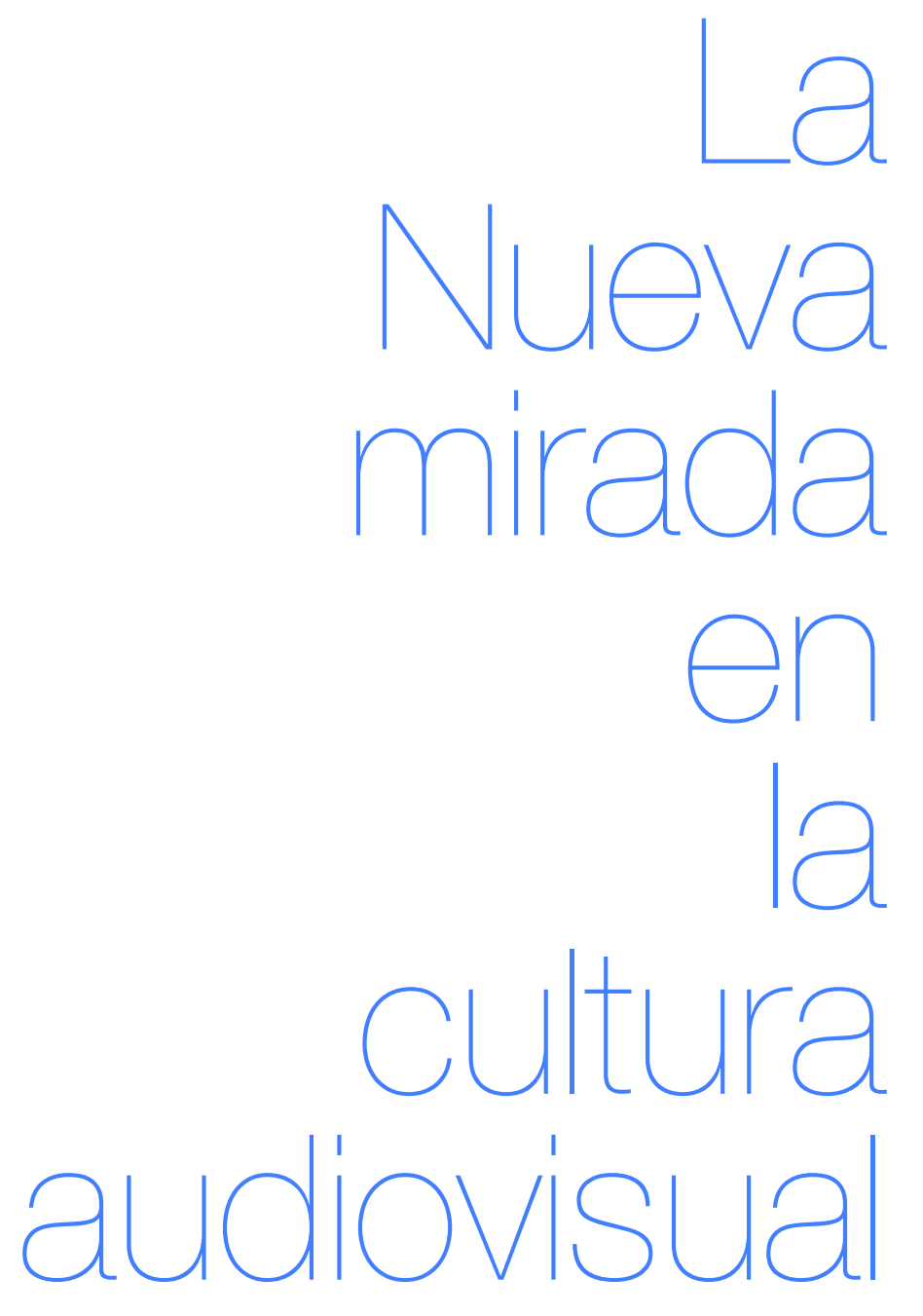

JOSE LUIS ZARCO SÁNCHEZ ${ }^{1}$

UNIVERSIDAD REY JUAN CARLOS

\footnotetext{
${ }^{1}$ La presente comunicación viene a ser una presentación o acaso resumen de intenciones de la tesis en curso, "Praxis fílmicas en la Web 2.0" bajo la dirección de Luis Alonso García en el programa de doctorado de cine Español de la URJC.
} 
Acabada recientemente la primera década del presente siglo, con lo que esto pueda acarrear (o no) como simbólica antesala de nuevos tiempos, seguimos la mayoría desconcertados sobre los límites y alcances del fenómeno audiovisual. Fenómeno que sin estar del todo clara su configuración durante el pasado siglo, ha entrado en este de lleno codificado a lenguaje binario, con lo que las posibilidades combinatorias de este nuevo objeto digitalizado se multiplican hasta límites aun hoy difíciles de vislumbrar. También por tanto los acercamientos teóricos, dadas las nuevas implicaciones que el fenómeno tiene a diferentes niveles, tanto económico, como cultural, político, estético o ético, por citar algunos.

Cabe señalar que la mayoría de las últimas tentativas por definir o teorizar sobre los aspectos relativos a la posible nueva forma que toma la imagen en movimiento tras su comunión con lo binario, siguen partiendo del objeto cinematográfico como antesala o campo sobre el que comparar, limitar o desarrollar el nuevo escenario digital, como así lo hizo Manovich (2001) hace ya una década o últimamente y en nuestro idioma La Ferla (2009). Todas estas propuestas parten del la concepción del fenómeno audiovisual predominante en el siglo pasado, el cine, como un objeto unitario y bien definido, obviando en ello las revisiones que sobre tal objeto realizaron en las últimas décadas autores como Gunning (1989) o Altman (1996). Si como señalan estos últimos autores, ese marco teórico se presentaba insuficiente en el pasado, más aun muestra su insuficiencia en el presente y no podemos acercarnos a fenómenos nuevos con los mismos horizontes analíticos que delimitaban el análisis fílmico antaño, no podemos desarrollar un análisis cinematográfico de objetos que no lo son.

Tradicionalmente tal marco de estudio se dividía en los tres niveles de producción, distribución y exhibición, siendo el primero el más importante a nivel teórico, pues en él se combinaban las teorías cinematográficas sobre lenguaje, estética y autoría con aspectos más exógenos y heterogéneos al hecho filmico, como la fotografía (en el sentido de iluminación de la escena a registrar), valores interpretativos, composiciones musicales, aspectos narrativos, etc. El cine seguía siendo esa suma de todas las artes que vindicaba Canudo. Señalemos ya, que dejamos de lado para nuestro análisis el llamado Séptimo Arte, centrándonos solamente en las posibilidades de la imagen móvil de registro en el marco de las tecnologías digitales. Serán posibilidades que por descontado seguirán siendo fuente de debate y discusión en el anteriormente referido campo cinematográfico. Serán sobretodo, esas posibilidades que se proclamaron como esencia de un supuesto arte cinematográfico, cuando en realidad son génesis de objetos muy distintos y en su mayor caso abortados o fagocitados por el modelo dominante de entender esa imagen móvil de registro, subordinada, la mayoría de las veces, a ser el apoyo mostrativo de una ficción narrativa. Objetos que sin embargo vuelven a tener una cierta e incluso notoria presencia en el nuevo marco de la digitalización audiovisual. Este nuevo marco se ve delimitado por dos factores principalmente. Por un lado la transcodificación digital que se está realizando sobre la totalidad de los registros culturales existentes, modificando así unos modos de consumo de esa cultura que pasan por la necesaria redefinición del mismo objeto cultural, sobretodo en la distancia que hay, en cuanto a sus posibilidades circulatorias se refiere, entre un libro y un ebook o entre el celuloide y el DVD. Por otro lado, la digitalización del utillaje que desde ahora se utiliza para crear los nuevos objetos culturales, lo que supone una redefinición de las rutinas y lenguajes con los que se da forma a esos 
objetos. Rutinas y lenguajes que gracias a la accesibilidad de lo digital son puestas en funcionamiento por sujetos no profesionales, por creadores autónomos e independientes del sistema mercantil que durante el pasado siglo ha dado sentido y forma al sector audiovisual. Ambos factores se unen en un nuevo modelo de creación e intercambio cultural que posibilita no sólo libre creación, sino además la posibilidad ilimitada de circulación del material.

\section{Digitalización Cultural}

Primeramente, esa digitalización de lo cultural, por mucho que desde diferentes ámbitos artísticos se quejen de la pérdida de esencia de este u otro objeto en su transcodificación binaria, es ya más un hecho consumado que otra cosa. Lo fotográfico, lo mélico, lo gráfico y lo pictórico pasan a ser un flujo discontinuo de ceros y unos con una misma naturaleza semiótica, al acabar todos como output en la misma interfaz que los integra y combina infinitamente. La digitalización de lo cultural, por así llamarlo, implica muchas cosas, pero sobre todo la posibilidad circulatoria de esa cultura a niveles nunca vistos hasta ahora. Circulación entendida tanto en el sentido tradicional, de movimiento de los contenidos de un sitio a otro, como en un sentido nuevo, de reconfiguración misma de esos contenidos que van mutando e integrándose con otros, formando nuevas configuraciones. Verdadera pérdida del aura de la obra de arte en la era de la infinita reproductibilidad binaria, verdadera conversión del arte en lo que es, pura comunicación, puro flujo de datos de entrada y salida. La nueva posibilidad comunicativa que abre esta digitalización está directamente relacionada con la capacidad natural de la red de situar todas las comunicaciones al mismo nivel jerárquico, por lo que la tradicional forma de comunicar unos pocos emisores a miles o millones, según sea el caso, de receptores, se desintegra en una red abierta a la creación e intercambios interpersonales de infinita conectividad pública. Es en definitiva, como señala Tim O'Reilly (2005), poseedor del registro del término web 2.0, la potencia de la red para aprovechar la inteligencia colectiva:

Los hipervínculos son los cimientos de la web. Cuando los usuarios añaden contenidos y sitios, quedan integrados en la estructura de la web por otros usuarios que descubren dicho contenido y enlazan hacia él. Tal como las sinapsis se forman en el cerebro y las asociaciones se fortalecen mediante la repetición o la intensidad, la trama de conexiones crece de forma orgánica como un fruto de la actividad colectiva de todos los usuarios de la web.

Como veremos, esa potencialidad comunicativo-creadora de la red afectará también a nuestro objeto audiovisual, en cuanto a la obsolescencia del modelo mercantil que desde hace más de un siglo regula el intercambio de obras, no sólo las audiovisuales claro está, y a las posibles consecuencias de un modelo de intercambio no jerarquizado. Escapa demasiado a nuestro propósito el análisis de las implicaciones que el actual debate sobre la libre o no circulación de contenidos e intercambio de archivos en la red está teniendo, sobretodo en España, pero no nos resistimos a relacionar la problemática, a niveles económicos, que puede 
suponer la pérdida del control sobre el negocio de los espectáculos masivos, entendido masivo como hecho por unos pocos para unos muchos (Wright, 1972). Internet con su fragmentación, sus Tags, sus blogs, sus foros y los demás modos de interacción y relación, atenta contra el negocio de la cultura de masas. Culturas de masas que como señala Benkler (2006: 296) «displaced folk culture y transfomed individuals and communities from coproducers and replicators to passive consumers». No sólo es una idea sobre el mismo mercantilismo de la cultura, es en definitiva el rebrote, al amparo de las posibilidades de la red, de la importancia de los Cultural Studies, representados sobretodo por un revitalizado John Fiske cada vez menos interesado por la televisión y un Henry Jenkins bautizado por algunos como el MacLuhan del siglo XXI. Compartimos con ellos al menos, cierta ilusión teórica por lo que pueda deparar el presente.

\section{Digitalización del utillaje audiovisual}

En segundo lugar es importante señalar las nuevas relaciones y las nuevas posibilidades que abre la digitalización del utillaje audiovisual. Estas nuevas relaciones tecnológicas, sin tener que llegar a ideales negropontianos, han posibilitado que una inmensa cantidad de personas tenga acceso al utillaje mínimo y necesario para componer una obra audiovisual y mostrarla o difundirla con total libertad, punto este último más importante si cabe, pues lo primero se podía hacer

\section{La tecnología digital ha afectado más al utillaje de registro de la imagen móvil que al de imagen fija de forma comparable a lo que representó para esta última en 1888 la cámara Kodak de bolsillo} casi con relativa facilidad a partir de la segunda mitad del siglo XX con los equipos de cinematografía ligera. La tecnología digital ha afectado más al utillaje de registro de la imagen móvil que al de la imagen fija, de forma comparable a lo que representó para esta última en 1888 la cámara Kodak de bolsillo, posibilitando el acceso a una variedad de videocámaras con una relación entre calidad de imagen y precio, imposible de pensar en términos de utillaje analógico.

La cuestión a dilucidar es, siguiendo el esquema de semiotecnias propuesto por Alonso García (2008), si puede configurarse una nueva relación entre el aparato, su lenguaje y su uso, relación que hasta hace una década invariablemente se decantaba por el uso de la cámara para hacer cine y poca cosa más, o al menos poca cosa más llegaba a ser accesible a la mirada, por razones de jerarquía mercantil como señalábamos antes. Relación que une, en esa comunión digital, no sólo al aparato de registro con el de edición o montaje, hoy ya siempre el computador, sino además con el canal de transmisión del registro, esa red formada por computadores conectados en una telaraña mundial. El abaratamiento de los equipos audiovisuales y la infinita posibilidad de circulación del material creado son así factores de una misma causa, el advenimiento de lo digital, que será la causa 
de que también cambie el uso que demos al aparato audiovisual como concepto genérico.

Semiotécnia puede definirse como «el cruce entre los rasgos otorgados a una forma expresiva y los atributos asignados a una forma comunicativa» (Alonso, 2008: 255-257); en el caso de nuestro perdido objeto cinematográfico, la forma expresiva sería la película tal cual la seguimos llamando hoy, y los atributos asignados a tal forma sería su visionado en el cine, ir al cine como práctica social o individual. Así pues, en el contexto actual, propiciado como decimos por el entorno digital, tenemos tan amplio abanico de propuestas de imagen en movimiento de registro que desbordan los límites y marcos del audiovisual como lo venimos entendiendo desde hace bastante tiempo. Los vídeos subidos a la red conforman una amalgama de formas expresivas heterogéneas, múltiples, diferentes y difícilmente abarcables en categorías integradoras que escapa al tradicional estudio de lo audiovisual en un panorama quizás comparable al periodo pionero del cinematógrafo, previamente a la homogeneización del fenómeno cinematográfico en el aparato-uso que da en llamarse cine. Y sea este periodo el que nos de la pista para, al menos delimitar el objeto sobre el que nos estamos refiriendo, esa imagen móvil de registro, fotográfico para más señas e incluso escasamente modificado en su concepto y materialización con la digitalización de la señal ${ }^{22}$ pues en el fondo hablamos de esos registros que están en la génesis de toda captura con el cinematógrafo, mucho antes de que el encuentro entre el aparato y un posible uso devenga en la ficción narrativa como dominante. Registros que actualmente desbordan, por su monstruosa cantidad, los límites de un posible análisis, siquiera taxonómico, pues por ejemplo nadie sabe a ciencia cierta cuantos vídeos hay subidos al canal Youtube, que además con un ratio de subidas de más 24 horas de vídeo por minuto $^{3}$ hace que incluso ese dato sea algo demasiado fugaz. Pero es indudable la popularidad que este tipo de comunicación audiovisual está alcanzando en nuestro días, pues un dato sí fácilmente comprobable, no sólo en YouTube sino

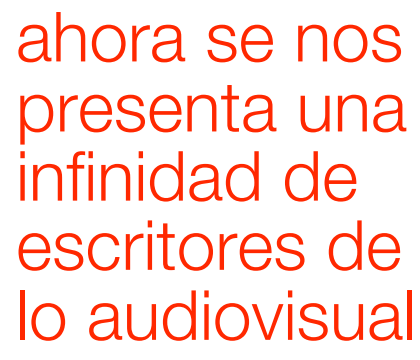
en la mayorías de canales dedicados al vídeo - canales que por otra parte han seguido un desarrollo similar a YouTube en

\footnotetext{
${ }^{2}$ Pues la videocámara, analógica o digital, sigue siendo esa cámara perspectivista de captación de información lumínica. Más aun vuelve hoy, con la masiva utilización de la nuevas cámaras fotográficas réflex para la captación de imagen móvil. Incluso la BBC aceptó en septiembre de 2010 las cámaras HD SLR (High Definition Single Lens Reflex) dentro su estándar tecnológico.

${ }^{3}$ Fuente: http://www.youtube.com/t/faq

4 Un partner es alguien que cobra por visitas a su(s) vídeo(s). Van desde profesionales a independientes profesionalizados, hasta particulares sin ánimo de lucro a los que el canal les ha ofrecido formar parte del Programa para Partners.

${ }^{5}$ Hoy por hoy lo que mayormente se sigue registrando del modo fotográfico suelen ser los actores, y cada vez más en la red los vídeos más visitados son grabaciones personales de momentos cotidianos con los bebés, la familia o los amigos. ¿Se podrá relacionar esta actitud con la progresiva desaparición de los actores en los Films, en una supuesta búsqueda por parte de la audiencia de la verosimilitud del registro espontáneo frente al actoral?
} 
cuanto a gestión y presentación de los vídeos-, es el del número de visitas que tiene cada vídeo. De esta forma además, se dejan de lado otras cuestiones, sin duda importantes para otros tipos de análisis, tales como qué tipo de vídeo que hay circulando en estos canales, sobre el nuevo apogeo de los videoclips, los aspirantes a directores, partners ${ }^{4}$ y demás productores o la utilización del canal para promociones de productos audiovisuales de naturaleza comercial. Será este último carácter de la mayoría de los vídeos que circulan por la red en canales temáticos, la de su pertenencia como segmento o en su totalidad a un producto audiovisual mercantil, sea película, programa televisivo, videoclip, gol del mundial o anuncio de un coche, el que nos haga descartarlos en nuestro análisis y acercarnos a aquellos que hayan sido realizados por particulares ajenos de una forma u otra al negocio audiovisual, en su calidad de simples registradores del mundo que los circunda. Es esa idea de registro, más que de creación audiovisual la que guía nuestro estudio, pues si no es suficiente la idea de que la mercantilización del producto dota a este de componentes formales quizás ajenos a lo que aquí nos interesa, valga al menos la idea de que posiblemente uno de los más grandes regalos tecnológicos para la imagen móvil de registro sea el de lo digital, ya que a la par del señalado abaratamiento del utillaje, ha propiciado la densificación del texto canónico cinematográfico en una multitud formal que sería la pesadilla por sobrepasada del sueño de Canudo, tanto, que incluso en ese objeto multiforme que es hoy el cine, la imagen móvil de registro es cada vez menos porcentaje del metraje de una película, ${ }^{5}$ dejándose por ende, cada vez más los registros para otras prácticas, para otros usos, ahora en la red. Pesadilla de la cinefilia, enriquecedor panorama que se abre a la imagen móvil.

Enriquecedor, y esta sería una de las principales tesis de este proyecto de investigación, porque el actual proceso productivo de imágenes a nivel mundial supera sin comparación el de acaso hace 20 años. ¿Sobreproducción de imágenes como protestan algunos? Una respuesta a esto se podría dar emparejando la escritura gráfica con la escritura audiovisual, y no es que digamos que el audiovisual sea un lenguaje, sino simplemente que hace no mucho tiempo sólo unos poco escribían para millones de ojos que sabían leer esas imágenes pero no escribirlas, o al menos eso era lo que se pensaba. Sin entrar en derroteros emancipadores, que los hay y variados, valga decir que lo que se nos presenta ahora es una infinidad de escritores de lo audiovisual. Una infinidad de escritores para una infinidad mucho mayor (la magia de lo binario hace esto posible, que lo infinito sea superable) de lectores, pero que a su vez son escritores o lo pueden ser sin ninguna traba. El supuesto hecho maravilloso que hacía que un niño quisiera ser director de cine al ver una buena película, se dispara de forma exponencial en la red con los vídeos de particulares (llamémoslos aun así), abriendo la puerta no sólo a la incentivación creativa sino al intercambio, participación grupal y mutuo apoyo y promoción. Será ya cosa de la sociología de la comunicación el estudiar cúanto tiempo pasa al día un joven adolescente o un jubilado, viendo y subiendo vídeos a Internet y cúanto viendo películas o televisión. Para nosotros es suficiente para interesarnos como objeto digno de atención el dato de que un vídeo como JK

Wedding Entrance Dance haya tenido en 
menos de dos años, y subiendo, más de 61 millones de visitas. No es el único caso claro está, y además la idoneidad del objetivo (y frío) dato de las cifras de visitas, se ve recompensado con la diversidad de practicas, modos o procederes distintos que podemos encontrarnos en la red bajo esa categoría de registros independientes. Sea el término independiente un concepto más abierto que ambiguo, ya que no crea confusión en cuanto a sobre qué mantiene su independencia, sobre lo mercantil, y abre el abanico a prácticas tan dispares, como Battle at Kruger y Noah takes a photo of himself every day for 6 years, totalmente diferentes entre si en modos, formas, intenciones e incluso protagonistas, pero ambas imágenes móviles registradas de manera totalmente independientemente.

En definitiva, la cuestión última que nos interesa es poder acercarnos al análisis de tales formatos con la intención de comprobar hasta que punto se están generando nuevas propuestas en la imagen filmica, por no decir cinematográfica y traer otras reminiscencias. Si ese, repetido tantas veces, encuentro entre el aparato y su uso nos tiene algo nuevo que ofrecer, en la teoría, esperemos que no muy peregrina, de que el hecho fímico, el acto audiovisual, tenga más oportunidades para su desarrollo a nivel formal, estético o siquiera simplemente comunicacional, cuantas más personas lo practiquen y menos esté ligado a intereses económicos o mercantiles. Por descontado que tales practicas son generadas por miradas que han sido eso más que otra cosa, miradas, y como todo acto comunicativo se verá limitado por las soluciones o lugares comunes, arraigados durante un siglo de cine y medio de televisión, pero sin duda abrirá la puerta a que esas mismas miradas en su conversión a creadoras también de imagen, conviertan por fin el acto de la comunicación audiovisual en un diálogo abierto a todos, y no en un negocio de sueños y estrellas más encaminado a entretener que a otra cosa.

\section{BIBLIOGRAFÍA}

ALTMAN, Rick (1996): "Otra forma de pensar la historia (del cine): un modelo de crisis". Archivos de la filmoteca, 22, pp. 6-19.

ALONSO GARCÍA, Luis (2008): Historia y praxis de los media: elementos para una historia general de la comunicación. Madrid: Laberinto.

BENKLER, Yochai (2006): The Wealth of Network. How Social Production Transform Markets and Freedom. New Haven and London: Yale University Press. Citado en BURGESS, Jean (2010): Youtube. Digital Media and Society Series. Cambridge (UK): Polity.

GUNNING, Tom (1989): "The Cinema of Attractions: Early Film, Its Spectator and the Avant-Garde". En Thomas Elsaesser y Adam Barker (ed.): Early cinema: space, frame, narrative. London: BFI, pp. $56-62$.

LA FERLA, Jorge (2009): Cine (y) digital. Aproximaciones a posibles convergencias entre el cinematógrafo y la computadora. Buenos Aires: Manantial.

MANOVICH, Lev (2001): The language of new media. Cambridge (Massachussets): The MIT Press.

O'REILLY, Tim (2005): What is Web 2.0? Design Patters and Business Models for the Next Generation of Software. O'Reilly Network.

[http://oreilly.com/web2/archive/what-is-web-20.html, consultado el 10/12/10] WRIGHT, Charles (1972): Comunicación de Masas: una perspectiva sociológica. Buenos Aires: Paidós, D.L. 